\title{
Deconstructing the 'Aporias' of Employee Codes of Conduct: The Zimbabwean Experience.
}

\author{
Langtone Maunganidze \\ Department of Sociology, Faculty of Social Sciences, University of Botswana \\ P Bag 00705, Gaborone, Botswana \\ E-mail: langtone.maunganidze@ mopipi.ub.bw
}

Doi:10.5296/jsr.v5i1.5269 URL: http://dx.doi.org/10.5296/jsr.v5i1.5269

\begin{abstract}
Employee codes of conduct have remained one of the most favoured templates for governing employee discipline and sustaining an ethical organizational culture in most contemporary establishments. However the numerous challenges and contradictions that confront both the construction and administration of the instrument have recently attracted a heightened interest from both scholars and industrial relations practitioners. Based on the findings from five selected Zimbabwean public sector firms, this paper mounts a critique of codes of conduct through the foil of postmodern deconstructionism and advances that there are aporias; that is, tensions and irresolvable contradictions between the logic and rhetoric of codes of conduct and their practice. The paper further argues that the codes are in a predicament rendering them to be at best only partially accurate and at worst misleading descriptions of the real organizational culture. The aporetic nature of codes of conduct as experienced by the variability and contradictions in the application creates possibilities of uncertainty and limitations in the management of employee discipline.
\end{abstract}

Keywords: Aporia, Code, Deconstruction, Discipline, Ethics, Postmodern

\section{Introduction}

Literature is replete with evidence showing the popularity of codes of conduct in creating and sustaining an ethical organizational culture by governing the actions and conduct of employees (Doig \& Wilson, 1998; Wortuba, Chonko \& Loe, 2001; Kenny, 2007; Erwin, 2011). Transcendent ideas about morality and human conduct are widely shared, guiding how people are treated but this occurs when parties experience procedural justice, fairness and favourable outcomes from case determinations and thus enhancing chances of perceived organizational support (POS) (Rhoades \& Eisenberger, 2002 cited in Shapiro et al, 2004). Codes of conduct (CC) are 'a web of rules' and 'binding ideology' to govern the employment relationship (Abbott, 2006, p. 193). Research on corporate codes of conduct has been 
traditionally influenced by systemic modernist theorizing which has often concentrated on their functionalist role and thus paying limited scholarly attention to their dark side particularly the blind spots or aporias. This paper attempts to deal with this neglect by mounting a critique of codes of conduct through the foil of postmodern deconstructionism and critical discourse analysis. The study is based on a qualitative analysis of experiences of five Zimbabwean public sector or state owned enterprises selected from sectors that include revenue administration (Firm A), telecommunications (Firm B), transport (Firm C), municipality or local authority (Firm D) and hospitality (Firm E).

The term aporia, as adopted from Derrida, refers to "a difficulty, impasse, or point of doubt and indecision" (William, 2009, p. 39). It also refers to 'an irreducible dilemma between two choices made insoluble by contamination, which would lead to unsatisfactory outcome' (Galetti, 2010, p. 93). For Jones (2003, p. 228), an aporia can be described as an irresolvable contradiction, a tension between demands that pull in two directions leading to situations of undecidability. Through deconstruction (Derrida, 1981) or critical discourse analysis (Fairclough, 1995; van Dijk, 1997) an attempt is made to expose these blind spots and dilemmatic foundations on which the codes are founded. What has been viewed as natural or taken for granted turns out to be arbitrary and problematical. According to Hurst's theory of 'plural logic of aporia' (Galetti, 2010), aporetic predicaments persist after one has circumvented logical structural errors. Deconstruction is an activity of reading which is attuned to seeking out those 'aporias' or blind spots within which a text involuntarily contradicts itself and hence, betrays the tensions existing between its logic and rhetoric (Chia, 1996, p. 187). The central argument of this paper is that there are blinds spots, tensions and contradictions between the logic and rhetoric of codes of conduct and their practice that render the management of employee discipline dilemmatic.

What is striking about Zimbabwean codes of conduct is the fact that their predicament is both institutional and structural. There is abundant evidence showing cases of partial or partisan execution particularly by employers despite it having been collectively conceived. Codes no longer function as signposts or descriptors of management's assumptions or a template against which to measure reality. In the absence of a supportive context especially the ethical framework, these codes are rendered 'invisible' and ineffectual, and thus having little influence on employee behaviour (Somers, 2001). Ethical codes of conduct are effective when enforced by sanctions and integrated into organizational every-day practice (Peterson \& Krings, 2009). The problem of failure to respect the codes and their subsequent ineffectiveness can be traced to their origins. Further challenges include the format and content of the code, implementation process and post-adoption administration (McGill \& Baetz, 2011, p.382). As the adoption of corporate codes become both the norm and legal requirement, the incidence of sincere, rhetoric based codes never designed to move beyond the cursory treatment of issues ('green-washing') is also likely to increase (Erwin, 2011, p. 536). This article proceeds as follows: it begins by contextualizing the problem by presenting a legal background to codes of conduct in Zimbabwe, followed by an overview of theoretical orientation. It discusses, drawing cases from selected firms, the deconstruction of the aporetic nature of the origins of codes of conduct, their purpose, implementation and post-adoption administration. It further examines the challenges and contradictions relating to issues of adherence to codes as ether prescription or 
promise and the effect on their application. The article's conclusion reflects on the central argument and suggestion for the need to deconstruct the power and domination discourse that circumscribe the origin, purpose and application of codes of conduct.

\section{Background}

Although there has been numerous reconfigurations to the approaches of managing workplace discipline in post-colonial Zimbabwe, the situation continue to be characterized by both the traditional and developmental approaches. Incidences of both distributive and procedural injustices that prevail in organizations render the distinction between the two effectively blurred. Rules that govern discipline by way of either negotiated codes or employer-driven corporate standing instructions or operating standards have been incessantly infracted by both management and employees.

This section provides an overview of the legal and political context of workplace discipline in Zimbabwe with specific reference to the private or non-state sectors which are governed by the Labour Act, 28: 01 as amended 1996, 2002 and 2005. However one needs to be cautious of this kind of meta-categorization given that for the purposes of the Act although parastatals or state-owned enterprises fall under the realm of non-state sector, their institutional ideology and control is still statist. At the turn of this century Zimbabwe was grappling with industrial relations challenges that had accompanied a plethora of anti-labour programmes such as ESAP and the controversial fast track land reform, which were both perceived as threats to job security and company profitability. State-labour tensions were further deepened following the 2000 general elections which saw the newly formed and labour based political party, Movement for Democratic Change (MDC) posting huge successes against the traditionally dominant ruling ZANU-PF. The effects of changes from the macro-environment either positively or negatively influence the way particular organizations manage their internal capabilities. At the height of the economic meltdown there was tension between the macro and micro aspects of co-evolution which negatively impacted on performance of most state owned enterprises. In order to improve productivity and economic efficiency the government embarked on a massive commercialization programme of state institutions that witnessed the birth of state owned enterprises or authorities across the economy. Names that come to mind include Civil Aviation Authority of Zimbabwe (CAAZ), Zimbabwe National Water Authority (ZINWA), Zimbabwe Revenue Authority (ZIMRA), Zimbabwe National Parks and Wildlife Authority (ZINPWA). The new organizations would generate revenues that would assist in insulating the state against unfavourable macro-economic environment that was characterized by ever rising inflation which was compounded by the country's international isolation. Most of such institutions had histories of corruption, massive brain drain and employee disengagement that required more accountable management systems. Notably, the rules and procedures of employee termination or dismissals that had previously prevailed in the sector did not allow managers and supervisors to expeditiously dispense of their cases. The logic of creating such state owned institutions operating outside the direct government influence or management was to allow them to manage employee discipline and industrial relations independently. The creation of works councils (section 25A) and employment councils (section 56 of the Labour Act, Chapter 28: 01 of 2002) and their role in the administration of workplace discipline particularly as regards dismissals brought about a 
new dimension to these newly established institutions.

Employment codes of conduct in Zimbabwe are registered by an employment council or works council in terms of section 101(1) of the Labour Act, 28: 01 and any decisions or determination shall be binding in respect of a particular industry or undertaking or workplace in Zimbabwe. Before the amendment, cases not determined within the prescribed period (thirty days) would have been referred to the Labour Tribunal. However challenges such as case determination delays due to shortage of human resources led to its replacement by the institution of Labour Court (Section 84 of new Labour Act). Organizations or firms that did not have any registered codes of conduct continued to handle their disciplinary cases by referring them to the Labour Relations Officers of the Ministry of Justice, Legal and Parliamentary Affairs in line with Section 93 of the same Act as read with the statutory instrument 130 of 2003 (Termination of Employment Regulations) for conciliation, mediation and arbitration. Both systems created serious backlog of cases and adversely affected both procedural and distributive justice. This situation created a deficit or blind-spot in the administration of workplace justice.

Codes of conduct for so many years in Zimbabwe have been in a way only 'voluntary' private regulations based on rule enforcement and not outcomes of any social dialogue between employers and employees. The participation of workers or their representatives have been very negligible. To-date there are many undertakings in Zimbabwe that continue to operate without any registered codes of conduct. However to ensure that all workplaces including those without registered codes were properly guided in handling disciplinary cases particularly dismissals, the Minister of Public Service, Labour and Social Welfare, published a model employment code of conduct (statutory instrument, 15 of 2006 by repealing 130 of 2003), in terms of section 101 (9) of the Labour Act. This effectively ended the role of labour officers in the handling employee discipline. Despite these legislative reforms there is no evidence in the legislation that makes it compulsory to have a code of conduct. There is effectively no need to have a registered code of conduct as the model provided by statute can still suffice. Unlike what Buzuidenhout and Jeppesen (2011) observed elsewhere in Southern Africa (South Africa, Lesotho or Swaziland), the Zimbabwean case does not give support to the view by other scholars (Jenkins et al, 2002; Barrientos \& Smith, 2007; Seidman 2007; Locke \& Romis, 2009, ) that codes of conduct often come into being when states follow repressive labour policies. Amendments to labour legislation in Zimbabwe with the support of other state driven policies such as land reform and indigenization programmes were actually perceived by industries as a direct attack on capital and populist attempts to protect the interests of labour.

One of the problems with both the principal Act (Chapter 28:01) and supporting statutory instruments, is the narrow restriction of employee discipline procedures to management of termination of employment and being conspicuously silent on fundamental aspects of industrial relations such as handling of employee grievances. Furthermore, only misconducts that are listed in section 12B of the Act and deemed as warranting dismissal are the ones listed in the model employment code of conduct. The legislation is 'blind' to numerous minor and moderate offences that may require immediate corrective action. The legislation assumes that every manager recognizes that disciplinary action was, in the first instance, educational 
and followed by punishment. In Zimbabwe, organizations may choose not to register their own code of conduct and only turn to the model code when confronted with a dismissal case. However the mere fact that they are self-imposed creates lack of a hard enforcement mechanism (Kenny, 2007). In such circumstances the code ceases to be a contractual promise that confers enforceable rights. All the five firms except one, company $\mathrm{C}$, had their own registered codes. It is argued that opting for the model one may be interpreted as lack of commitment or willingness or written pledge by the employer to establish standards that respected labour rights. This would be similar to an employer who did not provide an explicit contract of employment and leave the relationship in an implied state. It is only in the interest of the organization's reputation and economic interests to register its own code of conduct. However the dilemma is that this also may not happen in the absence of works council or employment council as prescribed by the legislation. The power to prescribe standards and to impose discipline is often challenged by individual employees and trade unions which render maintenance of discipline in the workplace often a fertile source of conflict at both individuals and collective levels (Grogan, 2009, p. 129).

\section{Theoretical orientation}

\subsection{Systemic modernism: logics of codes of conduct}

Systemic modernists and functionalists see harmony in the social world (Harcourt, 1997) and as such codes serve a unitary purpose in the creation and sustenance of organizational order and stability. Organizations are seen as harmonious, conflict free and tied together by a single organizational culture. Companies subscribing to this frame of reference should ensure that management has untrammelled prerogatives to control pace and processes of work. Codes of conduct, where they exist function as purely management tools for the suppression of internal tensions over distribution of organizational power by ensuring that management retains superior knowledge about the organization of work and has the authority to direct workers as it sees fit (Abbott, 2006, p. 192). Organizations subscribing to this paradigm often adopt the 'model' National Employment Code of Conduct or may design their own codes without any input from the employees. Following Dunlop's (1958) systems theory of industrial relations codes are driven by a unified concern for substantive and procedural work rules. They are supposedly generated from a shared ideology that legitimizes the roles of the actors and thereby enhance its own stability. Codes enhance integration and coordination in the management of discipline and thereby improving system effectiveness in fulfilling a given purpose (Cooper \& Burrell, 1988). They function as a measure of the degree of acceptance of organizational values, policies and procedures. Codes are important because they encapsulate the main principles of substantive and procedural fairness relevant to the various types of dismissal. Codes function as rule book that clarify the kind of behaviour expected or operate as mirrors to provide employees an opportunity to confirm whether their behaviour is acceptable or not (Schwartz, 2001). This facilitates organizational commitment and support of the organization. Internally created codes are seen as a way not only to self-regulate, but also to bolster organizational image and reputation (Kenny, 2007).

Although critical modernists (Cooper \& Burrell, 1988) share the pluralist view that divergence and conflict are specific expressions of the nature of the society they reject the 
notion that social systems are driven by common interests; preferring instead to see them as instruments of domination through which one group imposes its priorities on others (Harcourt, 1997, p. 465). Conflict is both rational and inevitable and requires to be regulated by institutions through accepted and codified procedures (Huzzard et al, 2004, p. 24). Joint regulation is seen as a mere temporary accommodation to capitalist work structures. Codes of conduct do not permanently reduce the power asymmetry between management and employees. The equal balance of power between the two is an illusion. Codes of conduct are part of technology that serves to reinforce the power and control of the advantage over the disadvantaged so that the later more effectively serve the interests of the former. They serve different and often conflicting functions for each of the key industrial relations actors; employees, employers and the state. As a result, codes are not necessarily products of a genuine need for a democratic dispensation in the workplace but conveniently crafted to secure and preserve sectoral interests.

\subsection{Critical discourse analysis: codes as text}

According to critical discourse analysis (CDA) (Fairclough, 1995; Dijk, 1997) discourse is thought to be represented by text and also shaped by social practices. Discourse analysis in the tradition of discursive traditions is inspired by Foucauldian concepts of knowledge and power. Oppression is largely invisible because it is encoded within institutions and discourses that appear as instruments of knowledge and not as sites of power. Disciplinary power is most potent and efficient when it operates through administrative rules rather than force majeure (McKinlay \& Starkey, 1998, p. 5). The code of conduct is one such hegemonic instrument. The process of developing the code involves subduing and co-opting dissenting voices through subtle dissemination of the dominant group's perspective as universal and natural, to the point where the dominant beliefs and practices become an intractable component of common sense. In a hegemonic regime, an unjust social arrangement is internalized and endlessly reinforced in institutions (Litowitz, 2000). That domination is often subtle, invisible, and consensual.

Codes of conduct should be understood according to power relations circumscribing their origin, purpose and application. This approach requires a deeply reflexive approach to recognize the rules of formation, and to understand the patterns of power relations. The appeal of discourse analysis inspired by Foucault has the potential to show the link between political rhetoric, and how discourses are created and maintained. As Foucault observed, (Hewitt, 2009, p. 5) “.... there are manifold relations of power which permeate, characterize and constitute the social body, and these relations of power cannot themselves be established, consolidated nor implemented without the production, accumulation, circulation and functioning of a discourse" (Foucault, 1980 p. 93). The application of the code of conduct is thus not a 'rational' process but a form of discursive 'policing'. Derrida sees such 'discursive domination' through 'techno-mediatic power' as conditioning and endangering democracy (Carter \& Jackson, 1998). It is a discursive strategy or a form of representationalism which hides or deflects inconsistencies and contradictions behind a wall of rhetorical and textual practices. The codes' 'reified' nature or entity-like stati with its imputed characteristics are outcomes of dominant members' own self-referential urge to create order and to bring to hand, 
and make more manipulable and controllable, that which is unwieldy, obdurate, intractable, or remote (Chia, 1996, p. 219). Any suspension or dismissal in terms of the code is presented as objective and hence legitimate and effectively less wicked.

The code of conduct contains a 'subtext' that is wholly or partially hidden (Donaldson, 2003). The hidden textual level or the hidden text (Kilduff, 1993) creates multiple interpretations. Given that all texts are political, the code of conduct that results from bargaining between managers and employees will be interpreted differently. To illustrate this point; I consider the Codes that are negotiated by works councils or NEC I Zimbabwe. In an organization such as firm A (revenue administration), where employees perceive low level organizational support and high level of victimization the code of conduct may serve as an insulator against the imposed shocks while for managers it may be an instrument for maintaining discipline and getting rid of 'bad apples'. Codes are managerial and legal tools (Adams, 2001, p. 200). The coming of the code can thus be celebrated for different reasons. Managers and employees have conflicting interests or stakes and as such codes cannot be reduced to the interests of one party. The situation differs with the case of a model Code, which in the Zimbabwean case is a statutory instrument and mostly adopted by organizations that do not have their own codes. Apart from one fundamental limitation of restricting its application to the management of dismissals, the list of 'serious misconducts' (S.I .15 of 2006 Section 4(a-h) p.82) allows multiple and sometimes conflicting interpretations. For the loyal and productive employees the code of conduct should protect them against both unfair labour practice and potentially inequitable rewarding systems.

\subsection{Postmodern deconstructionism: Codes as representation}

According to Chia (1996, p. 98) 'postmodernism' has been associated with 'the collapse of grand narratives' or 'resistance to modernist drives towards determinacy and consensus' (Lyotard, 1984), the crisis of truths, the replacement of the 'real with representational, (Gergen, 1999), and the privileging of 'difference over identity' (Cooper \& Burrell 1988; Lemert, 1992). Deconstructive practice involves 'undoing' or refers to 'dismantling' the conceptual oppositions in linguistic convention which have provided the bases for framing our modern experiences of social reality. It reveals the marginalized and problematical aspect of experiences which has been denied legitimacy within the dominant modernist discourse (Derrida, 1981, p. 93). Thus postmodern deconstructionism abandons reification of individual and macro-level explanations in favour of emergent process networks and heterogeneity of elements, events, micro-practices and processes which generate localized effects (Chia, 1996, p.115-116). Therefore to view codes of conduct as outcomes or symbols of industrial democracy is typical of systemic modernist theorizing where events in an organization are explained using an overarching 'grand theory'. As Martin (1990) puts it, deconstruction peels away the layers of ideological obscuration, exposes the suppressed conflict and focuses on multiple interpretations of a text in order to undermine all claims to objective truth. What is organized and representable can be set out in advance for our control and manipulation. In this process, a deliberate form of suppression occurs which remains hidden and inexplicable. Deconstruction involves demystifying a text, tearing it apart to reveal its internal, arbitrary hierarchies and its presuppositions. It lays out the flaws and the latent metaphysical structures 
of a text. A deconstructive reading of a text seeks to discover its blindness. One of the blind spots regarding codes of conduct and that require deconstruction is the conventional thinking that employee involvement in the drafting and formulation of codes makes implementation more democratic and easier. Does it make any real difference if workers are involved in the process? I argue that this form of worker involvement is effectively a form of collective bargaining meant to thaw the frozen fronts of industrial conflict. By providing workers or their representatives the opportunity to negotiate in the rule-making process; employers, through managers, gain an additional source of supervision over worker behaviour which they may not have been able to control in the absence of such institutions. As observed by Harbison (1954) (quoted by Jackson, 1991 in Blyton \& Turnball, 2004) for management this form collective bargaining by way of code of conduct may represent an attempt to establish a degree of joint control where formerly they did not even have that. The process reduces potential conflict that may arise from either suspensions or dismissals that are perceived to be illegitimate.

\section{Discussion}

\subsection{Prescription or promise?}

As a prescription, a code should assist in dealing with numerous curable diseases confronting the organization and operate as an appropriate tool to provide effective strategies to curb unethical conduct. As a promise, it should provide sufficient enthusiasm and trust among actors to depend or rely on it. This later metaphor evokes multiple interpretations. There are multiple stakeholders with divergent and conflicting interests in any organization. A code of conduct experiences an aporia when it is demanded in two directions. Determined in two ways, it has a double or 'divided duty.' (Derrida, 1992 cited in Jones, 2003). Management can equally use codes as a strategy in itself; that is a 'stage craft 'or a 'representation' or cynic manipulation. Organizations are political systems that function as instruments of domination, exploitation, control and manipulation (Morgan, 1997). Organizations are social and political phenomena of extreme complexity and this complexity is real not an illusion (Prince, 2007, 10). By involving employees and even clients in developing codes of ethics or conduct or ethical charters for the organization such as experienced in firms $A$ to $D$, the final product borne out of the process would appear less political and malicious. The involvement of workers representatives is a legitimating process that masks and kills off possible resistance (Prince, 2007). Codes of conduct are no longer seen as "the truth" but simply as privileged discourses that deny and silence competing and dissident voices. While promises may be more value driven than prescription, they are not necessarily effective. As a promise, a code of conduct may not only remain unfulfilled but reduced to a blank signpost.

As a prescription the codes serve to construct an administrative system which provides the basis for knowing in-advance. Thus, 'in-advance' knowing and representing are essentially the suppression of other scene, the 'un-ready' which forms the space in which representation occurs (Chia, 1996, p.142). When a code of conduct is introduced or implemented for the first time, it tends to effectively discredit all previous approaches. When codes of conduct were introduced in firm A (revenue administration) and C (transport) after the transformation of the companies from being state managed into autonomous parastatals, managers and supervisors began to act as if they had never been involved in any staff suspensions or 
dismissals before! This constructs rhetorically an argument in which it exaggerates all preceding approaches to discipline as flawed in order to make the new approach less illegitimate.

The categorization of codes as either prescription or promise needs deconstruction as it is misleading. In most organizations managers who strictly adhere to the provisions of the code do not necessarily uphold the values of the organization. If ethical conduct or practice is fully ingrained across the organizational structures one would logically notice a possible reduction or zero tolerance in disciplinary cases. It is striking indeed that in most of the organizations, the number of disciplinary cases or number of suspensions or dismissals handled are key performance indicators or variables on which managers are rated. There are obviously multiple interpretations to whatever figures one comes up. The frequency of terminations or dismissals in terms of provisions of the code does not necessarily indicate the truth about organizational culture. In all the five firms investigated, codes of conduct contain a section on 'Ethics or Principles of the Code' which are expected to guide managers and employees in dealing with ethical issues. However the problem is that more often than not managers have tended to follow rules or procedures stipulated in the Code at the expense of ethics. As a result most codes of conduct have been reduced to either 'penal' or 'rules' codes. Anyway, what is the difference between a Code of Conduct and Code of Ethics? The former version is often rules-based and the most popular in most organizations and intended to warn employees about conduct that would lead to disciplinary action. The later version is a values-based and endorses general ethical or moral principles which facilitate the building of organizational commitment that reflects acceptance of organizational values. Ethics are stronger than rules or procedures.

These codes may take a prescriptive rules-based approach that specifically identifies acceptable and unacceptable behaviours or a values-based approach that endorses general ethical or moral principles (McGill \& Baetz, 2011). The choice between shaping the organizational culture and effective legal enforcement is not an easy one? Detailed prescriptive codes of conduct describing compliance monitoring and progressive disciplinary measures are generally considered legally best practices for justifiable employee discipline. In general, codes are an outcome of protracted collective bargaining and whose application should provide a litmus test for industrial democracy in many organizations. Both parties to the agreement are obliged to respect both the principles and values on which it is based. However tensions and contradictions arise when either party particularly employees believe that the organization has failed to fulfill its contractual obligations by failing to abide by the same code whose birth it presided over. This results in mistrust and possibly conflict which will subsequently affect the implementation of the codes. Cases of workers committee members boycotting or being reluctant to partake in disciplinary procedures were evident across all the firms studied.

\subsection{The 'aporia' of conception: are codes conceived to be aborted!}

The metaphor of human abortion symbolizes the key idea of policy discourse which is a product of interaction within the organization and how it portrays actors' incessant infraction of its rules and procedures. The origins and motives of conception are as varied as those for 
abortion! Depending on one's culture or value systems, when conception that results from rape or incest may be considered 'unholy' and in such a situation abortion may be considered appropriate. Whose interests does the code serve? What are the costs of abortion or 'baby dumping? Abortion refers to the situation when management discards the code before implementing it. Departing from the provisions of the code by both parties particularly the executive represents what Beer (1992) referred to as synonymous to case of plans being conceived only to be aborted (cf. Camillus, 1997, p. 2) In line with this metaphor, 'baby dumping' may occur when abortion would have failed or when the other party reneges on its promises. This often occurs when management applies the code of conduct partially and selectively. Employees may also 'dumb' the code in cases where they deliberately ignore the provisions of the code that guide grievance procedures and use other ways of redress such as sabotage, working in complicit with offenders, or engage in employee crimes (Maunganidze, 2013).

In spite of the availability of seemingly sufficient legal or institutional framework and competencies for the effective implementation of the codes, managers continue to abort the codes or opt for alternative techniques such as constructive dismissal, intimidation, and targeted transfers. This often occurs when managers believe that adherence to the provisions was not in their best interest. In some cases management effectively frustrates the fair and impartial implementation of the code by being disrespectful to their own decisions. Examples identified include cases in which a manager in firm A who was chairperson of a disciplinary committee was disciplined by the executive after his committee had acquitted an employee whom the executive was convinced had committed the offence. The same manager was later suspended and dismissed from duty on other frivolous charges.

Codes of conduct have ceased to function as a moral campus for the just and fair management of employee discipline. The efficacy of codes of conduct to predict, intervene and enrich industrial relations outcomes for the benefits of all stakeholders is continuously threatened. The code is crafted, adopted and implemented after protracted collective bargaining sessions that are characterized by 'boxing and dancing' between management and worker representatives (Huzzard, Gregory \& Scott, 2004). Would workers really or genuinely cooperate in the administration of their own control? Is a code of conduct an outcome of 'win-win' or 'win-lose' situation. Is the 'boxing and dancing' exercise in the process of negotiating a code of conduct real or illusory? These and many other questions may not be adequately addressed in a single article. However, needless to mention that the ambiguous positions managers occupy as both representatives of employers (who in this study is the government) and also as employees in their own right, inadvertently leave them in continuous state of 'shape shifting'. During the period of conception they may overtly present themselves as real defenders of capital while at the same time being willing-fully blind to any possible loopholes in rules and regulations that may happen to serve them in future. In organizations where there is systemic or institutionalized corruption such as in Firm A, B and E; managers may act in complicit with predatory employees. It is strikingly interesting that in spite of the extensive training on the application of codes, numerous cases that are dismissed by courts on appeal on the grounds of technicalities remain a challenge. For example, why would a supervisor or manager with all the available resources and authority, fail without any 
reasonable ground to investigate cases within the code's prescribed time limits? And why would a manager appeal against the decision of his own lower committee? This is paradoxical and contradictory. Such and other many examples observed elsewhere in the paper demonstrate the prevalence of numerous 'aporias' or blind spots circumscribing codes of conduct in the public sector in Zimbabwe.

\subsection{Code of conduct training: Can ethics be taught?}

One of the requirements of a code for it to be legally binding or contractual is that it should have been disseminated in a manner that employees knew of its content and reasonably trained on it (Kenny, 2007, Christiana \& Gumbus, 2009; McGill \& Baetz, 2011). Is it possible for ethics to be constructed in the form of a code? Can ethics simply be reduced to a set of rules? Can trustworthiness be communicated or transmitted or taught? Ethics need 'to be established, then transmitted, and finally to be practised' (Wortuba et al., 2001, p. 61). The managers in particular are not necessarily inept or ignorant of the rules. Quite often in some organizations intensive induction on the content and application is provided for all supervisors and managers. Company rules and codes do not cover all situations even though there has been a flood of newly clarified, updated, and newly created standards of ethical behaviour in the workplace (Christiana \& Gumbus, 2009). Training employees on the codes is not a sufficient condition for compliance because codes are rarely the sole factor influencing decisions. Training of employees on codes of conduct is often not provided in most organizations and where it is provided it is done as part of induction to new staff. In one of the selected organizations in this study, the executive took all newly employed staff on a tour of one the central prisons in the capital Harare ostensibly to create a sense of awareness of the dangers of crime! Whether or not this has had any positive impact is beyond the scope of this paper. As Gumbus and Woodilla (2004) and Peterson and Krings (2009) observed, individual employees rely on various ethical decision making frameworks to guide their behaviours such as utilitarianism, individual rights, justice, virtue ethics or rules of thumb.

After a content analysis of schedule of offences prescribed in the codes of conduct in this study, together with the list of misconducts stipulated in the legislation, one discerns consistent pattern of behaviours that most employees would naturally have been aware of as examples of universal infractions or violations. For example, offences such as 'theft' or contravening values such as 'integrity, justice, sincerity, respect or punctuality' may not necessarily require formal organizational training. Consider a Zimbabwean High Court case number HC. B 1/98; in which the employee was reinstated after the company had failed to closely follow the procedures laid down in the code of conduct. The specific merits of the case were not considered. In another case (not brought before any court but handled by station management in terms of their Code), an employee slapped a client on the face during an altercation in front of colleagues and clients. Apparently the officer only received a written warning! There are numerous cases which may be used to illustrate so many blind spots or aporias that are encountered between justice and law or the rhetoric and practice of codes. 'Such actions by the employee represent irresponsibility, a failure to think an excuse or alibi through appeal to a code. To respond responsibly, to be polite or honest, one must not follow a code or mimic a set 
of 'rules of responsibility' (Jones, 2003, p. 229). Perhaps ethics can be taught but differently. As Derrida argued, the application of rules or law was not equal to ethics or justice. Ethics involved the break with conscience that results from clear knowledge of how to act in obedience to the law (Jones, 2003). Systemic institutionalization of values and ethics may be more effective than the conventional rule-driven in-house formal classroom or workplace simulative programmes all these firms tended to adopt. Law and justice, just as have been observed with values and rules, are complementary and any attempt at treating them as mutually exclusive renders the process of discipline management aporetic. Law alone leads to an ethically static system; justice alone leads to 'entropy' (systematic dissolution) (Galetti, 2010, p. 96).

\subsection{Adherence to the provisions of the Code.}

Strict adherence to the code has far reaching implications for justice in the workplaces. Strictly following the provisions of the code without allowing any room for variability and flexibility may also render the instrument obsolete. One of the challenges confronting the implementation of codes is not only its failure to work as guiding template for managing discipline but the extent to which they have inadvertently been substituted for good or model management practices. The choice between shaping the organizational culture and effective legal enforcement is also dilemmatic. In some organizations particularly those that are protectionist and paternalistic, codes of conduct are not viewed as an integral part of their culture but sides notes to be referred to only after rules have been breached. Thus codes have been transformed into 'codes of misconduct. As Camillus (1997) observed, the challenge of uncertainty and predicament of discontinuity was inevitable in the evolution of organizations. Some codes of conduct have not been reviewed for periods as long as 10-15 years and were now ecologically dwarfed. They could no longer present themselves as mechanisms to solve ethical problems. The youngest code of conduct in this study is that of firm C (transport) which was crafted and implemented in 2005 and with firm A's code coming as the oldest having been introduced in 2003. Apart from minor amendments, no code has yet been substantially reviewed. The Labour Act, under which all these codes of conduct were created, has undergone a number of changes since it came into operation in 1985, with major amendments being in 1992, 1996, 2002 and 2005. The codes of conduct as in all patterns of human action have encountered imperceptible and disjunctive shifts (Gergen \& Thatchenkery, 1998). The circumstances that prevailed during conception, at the time of implementation and the future are incongruent. Executives have become ingrained with beliefs about causes and effects that may not hold after the environment changes. The principles and procedures may also be inconsistent with the day-to-day practices for a getting a job done (McDonald \& Zepp, 1994, p. 205).

Strict adherence to provisions of the codes is not always a productive outcome. The introduction of new procedures in general and the management's strict adherence to the provisions have been accompanied by the death of managerial autonomy, flexibility and creativity. Given that discipline should be developmental, the implementation of the code should be guided more by values than rules and procedures. Strict adherences have reduced codes of conduct to standard operating procedures for use by supervisors and managers. 


\section{Conclusion}

This article sought to demonstrate the predicament arising from the contradictions and tensions that circumscribe the logic and rhetoric of employee codes of conduct and their practice. With the use of postmodernist thinking, the rationality and 'truth' characteristics that are often imputed to the origin, content and implementation and post-adoption process of employee codes of conduct have been debunked or deconstructed. Presenting codes by way of metaphors such as signposts, smoke detectors, text, or aborted plans, was meant to provide a critical review of their future as frameworks for defining, determining and changing the conduct and culture of organizations.

The article observed that the 'danger' with company codes is that they are likely to be at best only partially accurate and at worst misleading descriptions of the real organizational culture. The role of codes is to ensure that the organization's real substance (culture and identity) recedes from view. Statements of values and beliefs that are contained in most codes are often statements of aspiration or strategic intent of the executive rather than a shared reality (Doig \& Wilson, 1998). The appearance of objectivity masks ideological positions and fosters the illusion of consensus and certainty (Cooper \& Burrell, 1988). The selection and application of specific provisions of the code to particular circumstances is not an objective enterprise but a reflection of human preferences influenced by power, conflict and values. Codes operate as a grand theory which serves as an instrument of power because it enables one group; that is, managers to rationalize and legitimize their actions. It further provides a pretext for socially controlling or even exterminating workers that are classified as criminals or deviant in terms of the provisions of the code. As a form of 'disciplinary power' and 'social technology of control', codes of conduct, both enable and constrain productivity. The aporetic nature of codes of conduct as experienced by the variability and contradictions in their application creates possibilities of uncertainty and limitations as both a managerial and legal tool for dealing with discipline in the workplace.

\section{References}

Abbott, K. (2006). A review of employment relations theories and their application. Problems and Perspectives, 1/2006: 187-199.

Adams J; Taschian, A., \& Shore, T. (2001). Codes of ethics as signals of ethical behaviour, Journal of Business Ethics, 29: 199-211.

Barrientos, S., \& Smith, S. (2007). Do workers befit from ethical trade? Assessing codes of labour practice in global production systems. Third World Quarterly, 28(4), 713-29.

Blyton, P., \& Turnball, P. (1992). Reassessing human resources management. London: Sage.

Buzuidenhout, A., \& Jeppesen, S. (December, 2011). Between market, state and society: Labour codes of conduct in the Southern African garment factory. Development Southern Africa, 28 (5), 653-668. 


\section{Macrothink}

Camillus, J. (1997). Shifting the strategic management paradigm. European Management Journal, 15 (1), 1-7. London: Elsevier Science Ltd

Carter, P., \& Jackson, N. (1998). Negation and importance. In R. C. H. Chia, (ed.) In the realm of Organization: Essays on Robert Cooper (pp.188-212) London: Routledge.

Chia, R. (1996). Organizational analysis as deconstructive practice. New York: Walter de Gruyter.

Chia, R. C. H. (1998). In the realm of organization: Essays on Robert Cooper. London: Routledge.

Christiana, V., \& Gumbus, A. (2009). Shades of gray: Applying professional codes of ethics to workplace dilemma. Eastern Management Journal -Organization Management Journal, (6), 178-179.

Clegg, R S., \& Kornberger, M. (2003). Modernism, postmodernism, management and organization Theory. In, E. A Locke. (ed.). Postmodernism and management: Pros, cons and the Alternative research in the Sociology of Organizations. (pp 57-88). Oxford. UK, Elsevier Ltd.

Cooper, R. \& Burrell, G. (1988). Modernism, postmodernism and organizational Analysis: an Introduction. Organization studies, 9 (1), 91-112.

de Ville, J.(2011). Jacques Derrida: Law as absolute hospitality. Abingdon, Oxon; New York: Routledge.

Derrida, J. (1981). Positions. Chicago: University of Chicago press.

Doig, A., \& Wilson, J. (July, 1998). The effectiveness of codes of conduct. Business ethics, 7 (3), 140-149. Oxford: Blackwell publishers Ltd.

Donaldson, L. (2003). A critique of postmodernism in organizational studies. In E. A Locke. (ed.). Postmodernism and Management: Pros, Cons and the Alternative Research in the Sociology of Organizations. (pp 169-202). Oxford. UK, Elsevier Ltd.

Dunlop, P. (1958). Industrial relations systems. New York: Rhinehart \& Winston.

Erwin, P. M (2011). The Effect of code content and quality on ethical performance. Journal of Business Ethics, 95, 535-548.

DO1: $\quad$ 10.1007/s10551-010-0667-y.

Fairclough, N. (1995). Critical discourse analysis: the critical study of language. Longman: 
London.

Foucault, M. (1982). Afterword: The subject and power. In Dreyfus, H., and Rabinow, P. (eds.) Michel Foucault: Beyond structuralism and hermeneutics (pp. 208-226), Harvester Press: Hemel Hempstead.

Fox, A. (1974). Beyond contract: Work, power and trust relationships. London: Faber \& Faber.

Galetti, D. R. (2010). Looking for logic in Derrida: Assessing Hurst's 'Plural Logic of the Aporia'. Journal of Literary Studies, 26 (3), 84-109.

Gergen, K. J. (1999). An invitation to social construction. Oxford: Thousand Oaks.

Gergen, K. J. \& Thatchenkery, T. J.(1998). Organizational science in a postmodern context. In R.C.H. Chia (ed.). In the realm of organization: Essays for Robert Cooper (pp.15-42) London: Routledge

Grogan, J. (2009). Workplace law $\left(10^{\text {th }}\right.$ Ed.) Cape Town: Juta \& Co. Ltd.

Gumbus, A., \& Woodilla, J. (2004). Julia's dilemma. Eastern Management Journal -Organization Management Journal, 1(1), 19-26.

Harcourt, M. (April, 1997). Postmodernism: Implications for industrial relations. Indian Journal of Industrial Relations, 32, (4), 463-472.

Hassard, J., \& Parker, M. (1993). Postmodernism and organizations. London: Sage Publ. Ltd

Hewitt, S (2009). Discourse analysis and public policy research. Centre for Rural Economy Discussion Paper Series No. 24 October 2009. Newcastle University.

Huzzard, T., Gregory, D., \& Scott, R. (2004). Strategic unionism and partnership: Boxing and Dancing? New York: Palgrave Macmillan

Jaeger, J. (January, 2013). Codes of Conduct: Values or Principles-pased.? (pp 48-49). www.compliance.com..888.519.9200

Jenkins, R., Pearson, R., \& Seyfang, G. (2002). Corporate responsibility and labour Rights : Codes of conduct in the global economy. London: Earthscan.

Jones, C. (2003). As if business ethics were possible, 'Within such limits'. Organization, 10 (2), 223-248. 


\section{Macrothink}

Journal of Sociological Research

ISSN 1948-5468

2014, Vol. 5, No.1

Kenny, K.E. (2007). Code of conduct: Whether Wal-Mart's code of conduct creates a contractual obligation between Wal-Mart and the employees of its foreign suppliers? Northwestern Journal of International Law and Business, 27, 453-473.

Kilduff, M. (1993). Deconstructing organizations. Academy of Management Review, 18, 13-31.

Locke, R., \& Romis, M. (2009). The promise and perils of private voluntary regulation. labour standards and work organization in two Mexican garment factories. Politics and Society, 37(3), 319-51.

Locke, E. A. (2003). Postmodernism and management: Pros, cons and the alternative. Oxford. UK, Elsevier Ltd.

Lyotard, J.F. (1984). The Postmodern condition. Manchester: Manchester University Press.

Litowitz, D. (2000). Gramsci, hegemony, and the law. Brigham Young University Law Review, 0360151X, 2000, Vol. 2000 (2),515-551

Martin, J. (1990). Deconstructing organizational taboos: The suppression of gender conflict in organizations. Organization Science, 1(4), 339-59.

Maunganidze, L. (2013). Can occupational predation buy labour quiescence? Business and Management Research, 2 (4), 1-11. Toronto: Sciedu Press.

McGill, S., \& Baetz, M. (January, 2011). Technology use codes of conduct: is it a choice between shaping the organizational culture and effective legal enforcement? Employee Rights and Employment Policy Journal, 15:379-410

McKinlay, A., \& Starkey, K. (1998). Managing Foucault: Foucault, management and organization theory. In McKinlay, A. \& K. Starkey, (ed). Foucault, Management and Organization Theory (pp.1-13) London: Sage Publications Ltd.

Petersen, L-E., \& Krings, F. (2009). Are ethical codes of conduct toothless tigers in dealing with employment discrimination? Journal of Business Ethics, 85: DO1: 501-514. 10.1007/s10551-008-9785-1.

Prince, L. (2007). Organizational analysis: Notes and Essays for the Workshop held on 15-16 November, 2007 Slough, Berkshire.

Seidman, G.W. (2007). Beyond the boycott: Labour rights, human rights and transnational activism. New York: Rusell Sage Foundation. 


\section{Macrothink}

Shapiro, J. A-M., Shore, L. M., Taylor, M. S. \& Tetrick, L. E (ed) (2004). The Employment relationship: Examining psychological and contextual perspectives. Oxford: Oxford University Press.

Somers, M. J. (2001). Ethical codes of conduct and organizational context: A Study of the relationship between codes of conduct, employee behaviour and organizational values. Journal of Business Ethics, 30:185-195. Khuwer Academic Publishers.

Schwartz, M. (2001). The nature of relationship between corporate codes of ethics and behaviour. Journal of Business Ethics, 32: 247-262.

van Dijk, T. (1997). Discourse as social interaction. London: Sage Publications.

Williams, H. (2009) A handbook to literature. Upper Saddle River New Jersey: Pearson.

Wortuba, T., Chonko, L., \& Loe, T. (2001). The impact of code familiarity on manager behaviour. Journal of Business Ethics, 33: 59-69. 